\title{
Evaluation Research on Micro-blog Marketing Effect of 5A Scenic Spot in China
}

\author{
Jin-Ying WANG ${ }^{1, a, *}$, Yu-Kun GUO ${ }^{1, b}$, Yin $F_{A N G}{ }^{1, c}$, Xin-Ye ZHANG ${ }^{1, d}$ \\ ${ }^{1}$ Institute of Management, Southwest University for Nationalities, Chengdu, Sichuan, China

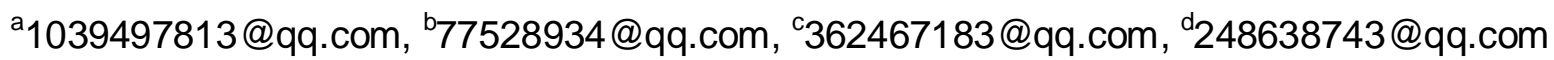 \\ *Corresponding author
}

Key words: Micro-blog, Marketing effect, 5A Scenic Spot, Principal component analysis (PCA).

\begin{abstract}
In order to evaluate the micro-blog marketing effect of the 5A Scenic Spots in China scientifically and provide some constructive suggestions, the thesis establishes a kind of evaluation index system on the basis of the user coverage, micro-blog active degree, and the propagation force. With Sina micro-blog as a platform, we select the officially certificated micro-blogs of $745 \mathrm{~A}$ Scenic Spots as data sources, and collect the related data. Using the principal component analysis (PCA), we find out the four principal factors which have great influences on the micro-blog marketing of scenic spots, i.e., the customers' attention to the resort, the scenic spots' emphasis on the micro-blog, the interaction between scenic spots and their fans, and the innovation degrees of scenic spots. Through analysis, the thesis classifies the official micro-blogs of these scenic spots: type I (wonderful), type II (fine), type III (ordinary), type IV (poor). The thesis also evaluates the basic situation of the 5A Scenic Spots in China and the shortcomings in micro-blogs' operation.
\end{abstract}

\section{Introduction}

Currently, the research field in tourism scenic spot micro-blog is blank, and there is no fixed standard to guide the establishment of micro-blog and to evaluate whether the tourism scenic spot micro-blog can reach the expected goal, which also needs to be discussed. Therefore, it's necessary to establish the operation effect evaluation system of tourism scenic spot micro-blog to evaluate the current situation of the development of micro-blog, so as to guide the establishment of tourism scenic spot micro-blog scientifically and orderly.

\section{Relevant research overview}

The relevant domestic and overseas researches about Micro-blog are mainly concentrated in three dimensions, i.e., the basic research of micro-blog, the dissemination study of micro-blog, and the value research of micro-blog. EvanWiiliams (2006), the founder of Twitter, is the first person to put forward the concept of micro-blog. Baidu Encyclopedia "micro-blog is a social media platform, through which users can share and communicate the information via WEB, WAP and other client components, and the text information is within 140 words and can be shared at any time". In recent years, some scholars define it as "a broadcasting media in the form of blog" [1].Neal Mr. Wiser (2009) thinks that micro-blog can make the enterprise find new opportunities[2].In the article, Bernard j. Jasen research micro-blog as a model of mouth marketing. Chris-Murdough summarizes the framework which has a certain universal adaptability of social media marketing metrics [3].

In the domestic, Micro-blog is new things. When analyzing the problem how to evaluate the effect about micro-blog marketing of 5A scenic spot, we found that the relevant scholars has conducted more detailed research about micro-blog management and marketing in enterprise. Du Zijian (2011) have studied the management of the enterprise micro-blog[4].Zhang Wenyong (2012) have pointed out the attention about enterprise micro-blog in the brand management, customer interaction aspect[5].Through correlation analysis and regression analysis, Jin Yongsheng (2011) have got a conclusion that there is positive correlation between the influence of enterprise micro-blog marketing effect and the number of published micro-blog and fans[6].Wang Lepeng, Yao Mingguang does a lot of research in new media marketing and micro-blog marketing[7]. 
On the whole, the research on micro-blog marketing is still in its infancy in academic circles, and it doesn't form a complete theoretical system framework. Evaluation research on micro-blog marketing effect of 5A scenic spot in China is less. Currently due to micro-blog of enterprises and personal develops very fast, a lot of basic research conclusion also needs to constantly update.

\section{Research method---principal component analysis (PCA)}

Principal component analysis is for the purpose of using the ideas of dimension reduction to put the index into a few more comprehensive indicators. When statistical method is used to study multivariate problems, it is hoped that in the process of quantitative analysis, we can put less variable and get more information [8]. Principal component analysis (PCA) can meet this requirement.

\section{The establishment of the index system and selection of scenic spots}

\section{The establishment of the index system}

On the basis of comprehensive analysis, from the coverage, the activity, the propagation force three aspects, we select 13 main indicators to build the evaluation index system.

Table.1 Evaluation index system on 5A Scenic Spot micro-blog marketing effect

\begin{tabular}{lc}
\hline First Level indicators & Second Level indicators \\
\hline Degree of coverage & $\begin{array}{r}\text { Number of fans X1/person,Number of active fans X2/person, Rate } \\
\text { of active fans X3 / } \%, \text { Number of plus V fans X4 / person }\end{array}$
\end{tabular}

The total number of micro-blog X5/article,Average number of Active released X6/day,Number of released X7/week, Original rate

The propagation $\mathrm{X} 8$ /article force Average number of comments X9/article,Average number of forwarded X10/article, Interactive rate X11 / \%,Number of keyword search about scenic area X12/forward, PR X13

\footnotetext{
* Note:Average number of comments or forwarding refers to the number blogger's recently 200 micro-blog is forwarded

PR(people - rank) refers to the quality index of fans, the PR ranges from 1 to 10 . The higher the $\mathrm{PR}$, the greater the quality of fans

Data record time: - 2013.3.31 17:00 2013.3.24 17:00
}

\section{The selection of scenic spots}

By the end of 2012 ,there are 119 5A Scenic Spots in China,and there are 74 5A Scenic Spots,opening official micro-blog on sina and get the certification.Many of them have very many points under the micro-blog account,for these scenic spots, this paper chooses the most representative account as the research object.

\section{Data collection}

Among these number in this paper, $\mathrm{X}_{12}$ is collected from sina micro-blog (http://micro-blog.com/) the remaining data mainly come from micro-blog (http://www.tfengyun.com/). But $\mathrm{X}_{4}$ from some scenic spots are not shown on the website (http://www.tfengyun.com/), so we collect this kind of data from sina micro-blog website. 


\section{Evaluation on micro-blog operation effect based on PCA method}

\section{The calculation process}

Firstly we need to standardize these observed dates of 74 5A Scenic Spots. The method we used is the method of standard deviation, namely:

$$
x_{i j}=\frac{x_{i j}^{\prime}-\bar{x}_{j}^{\prime}}{s_{j}^{\prime}}
$$

(Type: $x_{i j}$ is the new data after standardization; $x_{i j}^{\prime}$ is the original data, $\bar{x}_{j}^{\prime}$ is the sample expectations, $s_{j}^{\prime}$ is the sample standard deviation. After the standardization, the mean value of new data is 0 , and the standard deviation is 1 )

Table.2 Principal component characteristic value and contribution

\begin{tabular}{ccccc}
\hline component & Total & \% of Variance & Cumulative/\% & $\begin{array}{c}\text { principal component weight } \\
\text { after normalization }\end{array}$ \\
\hline F1 & 3.911 & 30.085 & 30.085 & 0.408 \\
F2 & 2.448 & 18.828 & 48.913 & 0.256 \\
F3 & 2.216 & 17.046 & 65.959 & 0.231 \\
F4 & 1.004 & 7.724 & 73.683 & 0.105 \\
\hline
\end{tabular}

* This table only shows the first four principal components

According to the 13observation index of the standardization which runs on Spass11.5, the KMO is 0.698 , and the test value of Bartlett is 0.Therefore, the data is suitable for principal component analysis. Through correlation coefficient matrix 13 indicators, We get the characteristic value of the principal component, the contribution rate and cumulative contribution rate (refer with: table 2).

According to the size of the characteristic value of each principal component and cumulative contribution rate, we determine the number of principal components. In this article we select the first four principal components whose eigenvalues are greater than 1.We regard F1, F2, F3, F4 as the principal component, and we can get the component matrix (refer with: Table 3).

Table.3 Component Matrix ${ }^{\mathrm{a}}$

\begin{tabular}{crrrr}
\hline variable & \multicolumn{4}{c}{ Component } \\
\cline { 2 - 5 } & \multicolumn{3}{c}{$F_{1}$} & \multicolumn{1}{c}{$F_{3}$} \\
\hline $\mathrm{x}_{1}$ & 0.8158 & -0.2292 & 0.0798 & -0.2306 \\
$x_{2}$ & 0.7083 & -0.1359 & 0.1975 & -0.3904 \\
$x_{3}$ & -0.3804 & 0.2443 & 0.8233 & -0.2285 \\
$x_{4}$ & 0.5752 & -0.3300 & 0.1708 & -0.1611 \\
$x_{5}$ & 0.5951 & 0.6452 & -0.1851 & 0.0782 \\
$x_{6}$ & 0.4913 & 0.7430 & -0.2815 & 0.0930 \\
$x_{7}$ & 0.3317 & 0.7027 & -0.1034 & 0.0785 \\
$x_{8}$ & 0.0206 & 0.7027 & -0.1034 & 0.0785 \\
$x_{9}$ & 0.6724 & -0.5706 & 0.1669 & 0.4135 \\
$x_{10}$ & 0.7819 & -0.2591 & 0.3628 & 0.3500 \\
$x_{11}$ & -0.0984 & -0.1719 & 0.3584 & 0.3293 \\
$x_{12}$ & 0.5717 & 0.4640 & 0.6049 & 0.4196 \\
$x_{13}$ & -0.4027 & 0.1265 & 0.2495 & -0.3061 \\
\hline
\end{tabular}

*Note: according to the SPASS11.5, we can get the component matrix directly. Specific ideas for: 
$l_{i j}=p\left(F_{I}, x_{j}\right)=\sqrt{\lambda_{i}} e_{i j}(i, j=1,2, \cdots, p)$ (Type: $\lambda_{i}$ is the eigenvalues of the correlation coefficient matrix, $e_{i j}$ is the corresponding eigenvectors)

\section{Correlation analysis of the data}

The table shows that in the first principal component, $\mathrm{F}_{1}$, six load values reached more than 0.5. At the same time the symbol is positive. They are $X_{1}, X_{2}, X_{4}, X_{9}, X_{10}, X_{12}$. Through the table2, we know $F_{1}$ mainly reflects the customer attention for tourism scenic spots.

In the second principal component, $\mathrm{F}_{2}$, the load value of $\mathrm{X}_{6}, \mathrm{X}_{5}, \mathrm{X}_{7}$ is greater than 0.6 and the difference is not big, and it reflects the tourist scenic spots place emphasis on micro-blog.

In the third principal component, $\mathrm{F}_{3}$, the load value of $\mathrm{X}_{3}, \mathrm{X}_{11}, \mathrm{X}_{13}$ is higher, and have reached more than 0.6 , and symbol is positive. It mainly reflects the interaction between scenic spots and fans.

In the fourth principal component, F4, the load value of $\mathrm{X} 8$ is relatively high; it can be seen as micro-blog innovation degree of tourism scenic spots.

According to the principal component (F1, F3, F3, F4)selected and the scores of 74 tourist scenic spots micro-blog(Through the operation of SPASS11.5, the date can be obtained), the four principal component scores were weighted and summed to gain composite scores for 74 tourist scenic spots. According to the scores, we sort 74 tourist scenic spots. The top ten scenic spots are listed in Table 4.

Table 4 Composite scores of scenic spots micro-blog operation effect in the top 10

\begin{tabular}{ccccccc}
\hline Micro-blog name & $F_{1}$ & $F_{2}$ & $F_{3}$ & $F_{4}$ & $\Sigma F$ & rank \\
\hline the Palace Museum & 5.67197 & -2.347 & 2.38285 & -1.1253 & 2.14931 & 1 \\
MissionHills & 1.36735 & 0.70513 & 1.22884 & 4.11414 & 1.45397 & 2 \\
OCT & 1.60856 & 1.35342 & -1.003 & 1.73721 & 0.95268 & 3 \\
Huangshan scenic area & 0.40214 & 1.71499 & 1.98349 & -1.5108 & 0.90298 & 4 \\
the shaolin temple's official & & & & & & \\
website & 1.38522 & 0.29843 & 0.49141 & 1.32696 & 0.8946 & 5 \\
Jiuzhaigou administration & 2.75554 & -0.338 & 0.34341 & -2.6541 & 0.83993 & 6 \\
Emei mountain scenic area & 0.98889 & 2.5873 & -1.2643 & 0.49844 & 0.82473 & 7 \\
Wuzhen tourism & 1.15438 & 0.79955 & 0.86483 & -0.657 & 0.80686 & 8 \\
The Summer Palace scenic spot & -0.4215 & 2.22721 & 1.34455 & 0.22044 & 0.73126 & 9 \\
Lushan scenic area & 1.31404 & -1.4196 & 1.05784 & 2.34359 & 0.66408 & 10 \\
\hline
\end{tabular}

The table 4 shows that comprehensive strength of 5A Scenic Spot micro-blog operation exists obvious difference. The Palace Museum scores 2.14931 ahead of other scenic spot, which is higher than Mission Hills 0.69534.

In the first principal component, $\mathrm{F}_{1}$, the top ten scenic spots are the Palace Museum, Jiu Zhaigou administration,OCT, Zhang Jiajie, Wu Lingyuan scenic area, Shaolin temple's official website, MissionHills, Lushan scenic area, Wuzhen tourism, Emei mountain scenic area, Mount Tai scenic spot respectively. China Huangshan scenic spot and the Summer Palace in the top 10 of overall ranking are replaced by Zhang Jiajie wulingyuan scenic spot and Mount Tai scenic spot.

In the second principal component, $F_{2}$, the top ten scenic spots are Emei scenic spot, the Summer Palace,the underground river of Lianzhou, Huangshan scenic spot, Mei country south wild goose tea field, Xi'an datang furong, OCT, Weihai Liu Gongdao scenic spot, Hengdian film and television official micro-blog, Mount Tai scenic spot.

In the third principal component,F3, the top ten scenic spots are Mountain Sanqing,the Palace 
Museum, Xishuangbanna tropical botanical garden, Huangshan scenic spot, Mei country south wild goose tea field, Wuxi film base, Wuxi Mount Ling, Yellow tree falls, the Summer Palace scenic spot, Qingming Shanghe garden official micro-blog. Thus, the interaction is very frequent between these scenic spots and fans.

In the third principal component,F3, the top ten scenic spots are MissionHills, Lushan scenic area, OCT, Mount Sanqing, Travel around Qinghai Lake, Shaolin temple's official website, Xishuang banna tropical botanical garden, Mountain Tianzhu in Anhui's official micro-blog, Mountain Baiyun scenic area, Mount Tai scenic spot. The micro-blog of these scenic spots and it is easily to get more fans

The four principal component scores were weighted and summed to gain composite scoresand the rabking for 74 tourist scenic spots. $(\Sigma F=0.408$ F1 F2 F3 $+0.105+0.231+0.256)$ F4), according to the $\Sigma \mathrm{F}>0.5,0<\Sigma \mathrm{F} \leq 0.5,-0.5<\Sigma \mathrm{F} \leq 0 ; \Sigma \mathrm{F}<-0.5$, these $5 \mathrm{~A}$ scenic spots can be divided into 4 categories: type I (wonderful), type II (fine), type III (ordinary), type IV (poor).In the 74 A scenic spots, type I (wonderful) accounted for $18 \%$, and type II (fine)accounted for $20 \%$ type III (ordinary)accounted for $46 \%$, type IV (poor)accounted for $16 \%$.

\section{Conclusion}

Main purpose of this article is through the PCA method to analyze the marketing effect of 5A scenic spots micro-blog. Through the research, we find status quo and existing problems of 5A scenic spot micro-blog marketing. The following:

1. There's some room for improvement to 5A scenic spots micro-blog operation.

2. The early development of scenic spots micro-blog just is regarded as a window to show some informationabout scenic spots, and it is not regarded as a portal of sales and services to study and develop.With the development of the tourism e-commerce, the new marketing mode represented by micro-blog will be a new development model of e-commerce.

3. The marketing function and service function of micro-blog become stronger and stronger. This also puts forward new requirements for the mode of management and sales to these scenic spots. But for these things, we can't impatient for success, they will take some time. So if we want to improve the marketing effect of 5A scenic spots micro-blog, we should know that there are several stages to experience

4. The management departments of scenic spots should fully understand the meaning of scenic spot microblog construction, and strengthen the guidance and support of scenic spots micro-blog, to make scenic spots micro-blog not only become an important platform to improve visibility and influence of the scenic spots, but also become a portal and a window of the interactive platform and marketing. And we can use the convenience of micro-blog to establish economic relations with tourists.

\section{Acknowledgement}

This research was financially supported by postgraduates' innovative research projects of Southwest University for nationalities. (CX2014SZ04)

\section{Reference}

[1] Baidu encyclopedia-sina micro-blog [OL] http://baike.baidu.com/view/2762127.htm.

[2] Neal Mr. Wiser. Using Twitter in the Enterprise. Market Watch: Technology, 2009 (8):16-19.

[3] Chris Murdough. Social Media Measurement: It's Not Impossible. Journal of Interactive Advertising, 2009 (10):94-95.

[4] Du Zijian. Enterprise micro-blog management handbook. Beijing: The printing industry press, (2011). 
[5] Zhang Wenyong. Enterprise micro-blog management analysis. Modern decoration, 2012:187.

[6] Jin Yongsheng. Short-term interaction model about enterprise micro-blog marketing effect and the number of fans.Management Science, 2011, 2 (4):71-83.

[7] Wang Lepeng. Discuss about the new media marketing of tourism enterprises. Journal of Inner Mongolia science and technology and economy, 2011,231 (5):31-32.

[8] Xu Jianhua. Mathematical methods in modern geography. Beijing: Higher education press, 2002:85-86. 